\title{
Search of the Emotional Design Effect in Programming Revised
}

\section{Nurminen, Mikko}

Springer International Publishing AG

2017-09-05

Nurminen , M , Leppänen , L , Väätäjä , H \& Ihantola , P 2017 , Search of the Emotional Design Effect in Programming Revised . in É Lavoué , H Drachsler, K Verbert, J Broisin \& M Pérez-Sanagustín (eds), Data Driven Approaches in Digital Education : 12th European Conference on Technology Enhanced Learning, EC-TEL 2017, Tallinn, Estonia, September pÿ12 15, 2017, Proceedings . Lecture Notes in Computer Science , vol. 10474 , Springer International Publishing AG, Cham , pp. 434-440, European Conference on Technology Enhanced Learning , Tallinn , Estonia , 12/09/2017 . https://doi.org/10.1007/978-3-319-66610-5_39

http://hdl.handle.net/10138/308330

https://doi.org/10.1007/978-3-319-66610-5_39

acceptedVersion

Downloaded from Helda, University of Helsinki institutional repository.

This is an electronic reprint of the original article.

This reprint may differ from the original in pagination and typographic detail.

Please cite the original version. 


\title{
Search of the Emotional Design Effect in Programming Revised
}

\author{
Mikko Nurminen $^{1 *}$, Leo Leppänen ${ }^{2}$, Heli Väätäjä ${ }^{1}$ and Petri Ihantola ${ }^{1}$ \\ Tampere University of Technology, Laborotory of Pervasive Computing, \\ Korkeakoulunkatu 3, 33720 Tampere, Finland, \\ (mikko.nurminen, heli.vaataja, petri.ihantola)@tut.fi, \\ University of Helsinki, Department of Computer Science, Yliopistonkatu 4, 00014 \\ Helsinki, Finland, \\ leo.leppanen@helsinki.fi
}

Keywords: Emotional design $\cdot$ Electronic learning material

\begin{abstract}
In this paper, we validate and extend previous findings on using emotional design in online learning materials by using a randomized controlled trial in the context of a partially-online university level programming course. For students who did not master the content beforehand, our results echo previous observations: emotional design material was not perceived more favourably, while materials' perceived quality was correlated with learning outcomes. Emotionally designed material lead to better learning outcomes per unit of time, but it didn't affect students navigation in the material.
\end{abstract}

\section{EMOTIONAL DESIGN IN ONLINE LEARNING}

With the increasing distribution - both spatial and temporal - of learning that is both allowed for and caused by online learning, the role of the lecturer is largely overtaken by the online learning material. In the light of the effect of emotions on learning outcomes [9], it seems reasonable to expect that eliciting an emotional response from the students with the online learning material would be similarly beneficial. Indeed, this can been achieved by what is known as emotional design of (online) learning materials, often defined as "redesigning the graphics [...] to enhance the level of personification and visual appeal of the essential elements in the lesson" [6]. The use of emotional design in on-line learning has gained wide attraction in the recent years $[11,10,8,5,7,4]$.

The effect of text-accompanying images on learning has been studied for decades, with a multitude of results that are somewhat hard to interpret as a whole. However the general trend seems to be that properly chosen textaccompanying images can result in better learning outcomes for students [3]. At the same time, even subject matter experts have trouble identifying problems students might have with certain text-image combinations [2]. This indicates that the interactions between the text and the accompanying visuals are complex and hard to understand. As Haaranen et al. after applying emotional 
design to enhance online study material in programming state: "if there is an emotional design effect, it is likely to depend in a complex way on the use of different colors, metaphors, and visualization types, and will not work equally well for all content and all kinds of learners" [4].

Inspired by both Haaranen et al. challenging the generalizability of their own results, and the recent discussions on the need for replication in relation to computer science education studies [1], we decided to replicate the previous experiment in a different context. We adopted the learning material used by Haaranen et al. into our CS1 programming course and conducted a randomized controlled trial seeking to understand how well students learn from the different versions of the material and how much time they spend with it. In addition, we seek to observe whether emotional design affects student navigation through the web pages in an online learning material.

The rest of this article is organized as follows: Section 2 details the research questions, the context of the study and the methodology. Section 3 details the answers to the research questions. Finally, Sections 4 discuss our results in the larger context of the previous work, and draw some final conclusions.

\section{RESEARCH DESIGN}

\subsection{Research Questions}

Our research questions extended from the previous work are:

RQ1: How is emotional design related to learning outcomes?

RQ2: How is emotional design correlated with student perceptions of material and visualization quality and helpfulness?

RQ3: How are student perceptions of material and visualization quality and helpfulness correlated with learning outcomes?

RQ4: Is emotional design correlated with material usage statistics?

\subsection{Data \& Context}

The experiment was conducted as part of the introductory programming course held at the Tampere University of Technology in 2015. The course participants were divided into two groups. One group acted as the control group and was shown a learning material with "traditional" visualizations. The treatment group was shown a learning material with "emotionally designed" visualizations. Both versions of the study material were the same as in the study we replicated with the exception that emotionally designed images were coloured as described in the future work section of the said article. The participants were free to take part in the experiment from any location.

The material consisted of 21 short pages of content with text and visualization, followed by a short questionnaire. The questionnaire consisted of the following questions, each answered on a Likert-scale from 1 to 5 , with 5 indicating the most "positive" response: 
Q1: How focused were you while reading the material?

Q2: How pleasant was the material to read?

Q3: How understandable was the material?

Q4: How well did the visualizations help you to learn?

Q5: How pleasant were the visualizations?

Participants were also to answer two questions regarding the material they had just completed reading, as well whether they would have been able to successfully answer said questions before reading the material. These questions were used to assess how well the participants had learned the material. The two questions used to assess student's comprehension and transfer of information were:

1. Weekly exercise 10.1: Based on what you read, describe what is meant by object-oriented programming.

2. Weekly exercise 10.2: What kind of objects would you use in a program, that keeps the records of a hotel's room bookings? Give an example of how these objects would communicate?

\subsection{Methodology}

As the students browsed the online learning material, their page visits were recorded. For each page view, we collected: student ID, the page, the time at the beginning of the page visit and the time at the end of the page visit.

All those participants that indicated in the questionnaire that they already knew the content beforehand and would have been able to answer the questions correctly even before reading the material were excluded, as they wouldn't need to study the material and were likely to just rapidly click through the material to get through it. These eliminations reduced the study to population of $n=206$ participants. In this filtered population, the control and treatment groups had $n=107$ and $n=99$ participants, respectively. Based on the survey in the beginning, there were no significant differences between the groups.

The participant answers to the two material related questions were graded on a binary scale: if the participant demonstrated that he or she had understood the material well enough to correctly answer a question, a score of 1 was given for that question. If the participant failed to demonstrate sufficient understanding of the material, a score of 0 was given.

\section{RESULTS}

\section{RQ1: Emotional Design and Learning Outcomes}

Subjecting the learning outcomes of the treatment and the control group to a Kruskal-Wallis analysis produced the following result: The treatment group $($ Mean $=1.58$, St.Dev $=0.54)$ and the control group $($ Mean $=1.38$, St.Dev $=0.56$ ) have different mean ranks with $p=0.009$. Thus, emotionally designed visualizations led to better learning outcomes but the effect is rather small: both groups are within one standard deviation of each other. 


\section{RQ2: Emotional Design and Participant Perceptions of Quality}

No statistically significant difference was found between the control group and the treatment group for any of the questionnaire questions, once a Holm correction for multiple comparisons was applied. While minor differences in means were observed, the means of the groups are always within half of a standard deviation of each other. Thus, the results related to RQ2 are inconclusive. The statistics are tabulated in Table 1.

\section{RQ3: Participant Perceptions of Quality and Learning Outcomes}

In order to answer our third research question, we searched for correlations between learning outcomes and student perceptions of learning material quality as reported in the final questionnaire. The results are tabulated in Table 2.

All questionnaire factors exhibited a statistically significant correlation with learning outcomes. Perceiving the material as pleasant to read, easy to understand, the visualizations as helpful and pleasant, as well as feeling focused are all as factors positively correlated with learning outcomes.

\section{RQ4: Emotional Design and Material Usage}

In order to answer our fourth research question, we observed two key material usage statistics: time spent on material and amount of backtracking. We defined backtracking as user moving to a material page they had already opened.

Both groups exhibited very few backtracking events. A Kruskal-Wallis test failed $(H=0.40, p=0.51)$ to show any statistical difference in the mean ranks between these two groups in the amount of backtracking events.

Next, we defined time-on-material as the time difference (in seconds) between the start time of the first material visit and the time when the user closed a nonquestionnaire material page for the last time. Kruskal-Wallis failed to show any statistically significant difference between the treatment and the control group for time-on-material, with $H=2.07$ and $p=0.15$.

Table 1. Answers to a questionnaire on material and visualization quality and helpfulness. "p" is the uncorrected p-value produced by a Kruskal-Wallis analysis. * indicates statistical significance at $p<0.05$ before a correction for multiple comparisons is applied, ${ }^{* *}$ indicate that the result is significant at $p<0.05$ after the correction is applied.

\begin{tabular}{l||c|c||c|c||c} 
& \multicolumn{2}{c||}{ Control } & \multicolumn{2}{c||}{ Treatment } & \\
& Mean & S.Dev & Mean & S.Dev & $\mathrm{p}$ \\
\hline \hline How focused were you while reading the material? & 3.38 & 0.86 & 3.42 & 0.79 & 0.94 \\
\hline How pleasant was the material to read? & 3.57 & 0.87 & 3.66 & 0.95 & 0.37 \\
\hline How understandable was the material? & 3.82 & 0.86 & 3.85 & 1.01 & 0.52 \\
\hline How well did the visualizations help you learn? & 4.22 & 1.35 & 4.02 & 1.06 & $0.05^{*}$ \\
\hline How pleasant were the visualizations? & 3.74 & 0.98 & 4.01 & 1.03 & $0.03^{*}$
\end{tabular}


Table 2. Correlations of participant answers to learning outcomes. "r" and "p" are the Pearson's correlation coefficient and its accompanying (uncorrected) p-value. ** indicate that the result is significant at $p<0.05$ after the correction is applied.

\begin{tabular}{l||c|c} 
& $\mathrm{r}$ & $\mathrm{p}$ \\
\hline \hline How focused were you while reading the material? & 0.15 & $0.03^{* *}$ \\
\hline How pleasant was the material to read? & 0.18 & $<0.01^{* *}$ \\
\hline How understandable was the material? & 0.26 & $<0.01^{* *}$ \\
\hline How well did the visualizations help you learn? & 0.21 & $<0.01^{* *}$ \\
\hline How pleasant were the visualizations? & 0.21 & $<0.01^{* *}$
\end{tabular}

\section{DISCUSSION AND CONCLUSIONS}

The results presented in Section 3 show that the treatment group that was shown emotionally designed visualizations had slightly better learning outcomes than the control group. At the same time, the results fail to show any statistically significant difference in the time used to read the material between the treatment and the control groups. When looking at individual results, our findings seem to be opposite to those reported in Haaranen et al. [4], where it was found that the treatment group and the control group had similar learning outcomes but that the treatment group spent less time in the material. Yet when the combinatorial effect of the findings is considered for both this research and Haaranen et al. [4], a similarity is found: In both studies, the treatment group "learned more per unit of time", so to speak. This result is also in line with the work of such authors as Heidig et al. [5], including in that the observed effect is rather small.

Our results pertaining to RQ 3 - whether perceptions of material quality and pleasantness are related to learning outcomes - further corroborate the overall result presented above: participant perceptions of material and visualization quality, pleasantness and understandability were all positively correlated with learning outcomes. This result, too, is in line with previous studies [5].

In this light, our answer to RQ 2 - whether participant perceptions of material quality were different between the treatment and the control group - are curious. While the treatment group displayed marginally better learning outcomes and student perceptions of material quality and pleasantness were correlated with learning outcomes, no statistically significant differences were observed in the groups' answers to the questionnaire on material quality and pleasantness.

Despite the failure to detect any difference in the backtracking behaviours of the groups, our view is that these findings indicate that emotional design helps the students assimilate knowledge, at least insofar as measured by our metrics of learning outcomes. Furthermore, our results seem to indicate that student perceptions of material quality and pleasantness are related to learning outcomes. Yet surprisingly, said perceptions seem to not be affected by emotional design. This somewhat counter-intuitive result warrants further study.

The generalizability of the results presented here is mostly limited by two factors: the homogeneousness of the participant population and the context of the study. The participants largely come from a socially homogeneous population 
and from a relatively narrow spread of economic and educational backgrounds. Similarly, as the study was conducted only in the context of one course of a single subject, whether the results generalize to other subjects is as of now unknown. At the same time, authors are unaware of any reasons why these results would fail to generalize within the context of higher education.

A further limitation is that students' learning was assessed by their answers to two questions that were graded on a binary scale. This rather narrow spectrum could have hidden some smaller trends in learning outcomes. Similarly, as the learning outcomes were only assessed immediately after the students had completed reading the material, any possible effects of emotional design on long-term retention are unknown within this study.

\section{References}

1. Ahadi, A., Hellas, A., Ihantola, P., Korhonen, A., Petersen, A.: Replication in computing education research: researcher attitudes and experiences. In: Proc. of the 16th Koli Calling International Conference on Computing Education Research. pp. 2-11. ACM (2016)

2. Benson, P.J.: Problems in picturing text: A study of visua/verbal problem solving. Technical Communication Quarterly 6(2), 141-160 (1997)

3. Carney, R.N., Levin, J.R.: Pictorial illustrations still improve students' learning from text. Educational psychology review 14(1), 5-26 (2002)

4. Haaranen, L., Ihantola, P., Sorva, J., Vihavainen, A.: In search of the emotional design effect in programming. In: Proc. of the 37th International Conference on Software Engineering - Volume 2. pp. 428-434. ICSE '15, IEEE Press, Piscataway, NJ, USA (2015)

5. Heidig, S., Müller, J., Reichelt, M.: Emotional design in multimedia learning: Differentiation on relevant design features and their effects on emotions and learning. Computers in Human Behavior 44, 81 - 95 (2015)

6. Mayer, R.E., Estrella, G.: Benefits of emotional design in multimedia instruction. Learning and Instruction 33, 12 - 18 (2014)

7. Navarro, O., Molina, A.I., Lacruz, M., Ortega, M.: Evaluation of multimedia educational materials using eye tracking. Procedia - Social and Behavioral Sciences 197, 2236 - 2243 (2015), 7th World Conference on Educational Sciences

8. Park, B., Knörzer, L., Plass, J.L., Brünken, R.: Emotional design and positive emotions in multimedia learning: An eyetracking study on the use of anthropomorphisms. Computers \& Education 86, 30 - 42 (2015)

9. Pekrun, R., Goetz, T., Titz, W., Perry, R.P.: Academic emotions in students' selfregulated learning and achievement: A program of qualitative and quantitative research. Educational psychologist 37(2), 91-105 (2002)

10. Plass, J.L., Heidig, S., Hayward, E.O., Homer, B.D., Um, E.: Emotional design in multimedia learning: Effects of shape and color on affect and learning. Learning and Instruction 29, $128-140$ (2014)

11. Um, E., L., P.J., O., H.E., Homer, B.D.: Emotional design in multimedia learning. Journal of Educational Psychology 104(2), 485 - 498 (2012) 